\title{
Semen affects the biological behavior of HeLa cells by altering ERK signaling
}

\author{
Zhi-Qiang Guo, Dan-Dan Zhang, Li Pang, Yu-Ting Wang, Pin Cao, Shu-Lan Zhang
}

Department of Gynecology and Obstetrics, Shengjing Hospital of China Medical University, Shenyang, China

Submitted: 8 December 2018

Accepted: 6 January 2019

Arch Med Sci 2020; 16 (4): 915-923

DOI: https://doi.org/10.5114/aoms.2019.81738

Copyright $\odot 2019$ Termedia \& Banach

\section{Abstract}

Introduction: The aim of the study was to investigate the effects of human semen on the proliferation, survival, migration and invasion of HeLa cervical cancer cells by analyzing the extracellular regulated protein kinase (ERK) pathway.

Material and methods: HeLa cells were stimulated with different concentrations of human semen. MTT assay was used to analyze the effects on cell proliferation. Apoptosis in the different experimental groups was quantified by Annexin V-FITC/PI staining. The effect of seminal plasma on in vitro invasiveness of cells was evaluated using transwell assay. Western blotting was used to evaluate ERK pathway activation.

Results: Human semen promoted HeLa cell proliferation; ERK1/2 phosphorylation and c-myc expression also increased with increasing semen concentration. U0126 inhibited semen-induced ERK1/2 phosphorylation, c-myc upregulation and cell proliferation. Compared with the control group, semen did not significantly affect the apoptotic rate of HeLa cells $(p>0.05)$. The transwell assays showed that compared with the control group, the number of invading cells increased significantly with increasing semen concentration, and the difference was significant $(p<0.05)$ when $1: 50$ semen was added, suggesting that semen promotes the invasion of cervical cancer cells. Western blotting indicated that ERK $1 / 2$ phosphorylation began to increase when 1 : 100 semen was added; with increasing semen concentration, ERK1/2 phosphorylation was significantly up-regulated, and the expression of its downstream target gene, c-myc, was also up-regulated $(p<0.05)$.

Conclusions: Semen promoted the proliferation of HeLa cells by activating the ERK pathway and showed increased tumorigenic potential in vivo. Human seminal plasma might be a potential factor contributing to the development of cervical cancer.

Key words: semen, HeLa cell, ERK, proliferation, invasion.

\section{Introduction}

Cervical cancer is one of the most common gynecological malignancies, with an incidence rate only second to breast cancer [1]. In China, there are approximately 100,000 new cases each year, accounting for $20 \%$ of the total cases worldwide. Many epidemiological and molecular biology studies have confirmed that human papillomavirus (HPV) infection is the most important risk factor for cervical cancer. HPV DNA can

\author{
Corresponding author: \\ Shu-Lan Zhang PhD \\ Department \\ of Gynecology \\ and Obstetrics \\ Shengjing Hospital \\ China Medical \\ University \\ 36 Sanhao St \\ Heping Qu \\ Shenyang, China \\ E-mail: zhangsl_med@126. \\ com
}


be detected in $99.7 \%$ of cervical cancer specimens [2]. The HPV infection is a sexually transmitted disease that is associated with sexual behavior. In sexually active women, the lifetime infection rate for at least one type of HPV is $82 \%$; however, less than $5 \%$ of HPV infections develop into cervical cancer [3]. In other words, other synergistic risk factors (immune status, genetic factors or physical and chemical factors) prevent the HPV infection from being eliminated by the human body; thus, continuous HPV infection gradually develops into cervical intraepithelial neoplasia (CIN) and eventually cervical cancer [4].

Among these synergistic risk factors, whether long-term stimulation by semen on cervical epithelial cells can induce cervical lesions or promote the development of cervical cancer has not been determined. Several studies have shown that activation of extracellular signal regulated kinase (ERK), a component of the mitogen-activated protein kinase (MAPK) family, has a profound effect on the development and progression of cervical cancer [5-7]. Hence, the goal of our current study was to determine in vitro effects of semen stimulation using the cervical cancer cell line HeLa.

\section{Material and methods}

\section{Reagents}

Cell lines and reagents included: HeLa human cervical cancer cell line (Beijing Concord Cell Center, Beijing, China), fetal bovine serum (Beijing Yuanheng Jinma Biotechnology Development Co., Ltd., Beijing, China), DMEM (HyClone, Pittsburg, PA, USA), dimethyl sulfoxide (DMSO; Sigma, St. Louis, MO, USA), MTT (Amresco, Solon, OH, USA), Lowry protein quantitation kit (Keygen Biotech, Nanjing, China), anti-human p-c-Raf monoclonal antibody, anti-human p-ERK1/2 monoclonal antibody, anti-human ERK1/2 monoclonal antibody and anti-human c-myc monoclonal antibody (all from Cell Signaling Technology, Danvers, MA, USA).

\section{Instruments}

Instruments included a constant temperature water bath (Shanghai No.7 Medical Devices Factory, Shanghai, China), DU60 Violet Spectrophotometer, Flow Cytometer, Continuous Light Microplate Reader, Miniature Vertical Electrophoresis (Beekman Biotechnology, Philadelphia, USA), Inverted Electron Microscope (Olympus, Tokyo, Japan) and the SensiAnsys image analysis system (Shanghai PeiQing Biotechnology Co., Ltd., Shanghai, China).

\section{Seminal plasma preparation}

Semen were collected from three healthy (age range: 25-27 years) male volunteers through masturbation approved by the local ethics committee. The semen samples were confirmed to be negative for HPV DNA using real-time polymerase chain reaction (PCR). Seminal plasma was isolated using the Percoll density gradient centrifugation method as described previously $[8,9]$, sub-packed and stored at $-70^{\circ} \mathrm{C}$ for future use.

\section{Cell culture and in vitro proliferation test (MTT assay)}

Cells in the logarithmic phase were digested with $0.25 \%$ trypsin, and the cell concentration was adjusted to $5 \times 10^{4}$ cells $/ \mathrm{ml}$. The cells were then inoculated onto a 96-well plate, using $200 \mu \mathrm{l}$ per well. The cells were divided into the following groups: $1: 100$ semen + HeLa cell group, $1: 50$ semen + HeLa cell group and $1: 10$ semen + HeLa cell group; each group was set up in four parallel wells. After $24 \mathrm{~h}$ incubation, $20 \mu \mathrm{l}$ of $5 \mathrm{mg} / \mathrm{ml}$ freshly prepared 3-(4,5-dimethyl-thiazol-2-yl)-2,5-diphenyl tetrazolium bromide (MTT) was added into each well and incubated for $4 \mathrm{~h}$. The culture medium was aspirated and $150 \mu$ l of DMSO was added to each well and shaken for $10 \mathrm{~min}$ at room temperature, followed by 30-min incubation at room temperature. The plate was placed in a microplate reader to detect the optical density (OD) at $490 \mathrm{~nm}$. The average OD of parallel wells was used as the OD value for each group. The above experiments were repeated three times and statistically analyzed.

\section{Apoptosis test}

The Annexin V-FITC/propidium iodide (PI) method was used to detect apoptosis in each group. Cells from the different groups were collected and adjusted to $1 \times 10^{6}$ cells $/ \mathrm{ml}$, then washed twice with cold PBS and resuspended in $1 \times$ Binding Buffer. Next, $100 \mu \mathrm{l}$ of cell suspension from each group was transferred to new tubes, and $5 \mu \mathrm{l}$ of Annexin V-FITC and $5 \mu \mathrm{l}$ of PI were added, and the reaction system was shaken followed by 15 min incubation at room temperature in the dark. Afterwards, $400 \mu \mathrm{l}$ of $1 \times$ Binding Buffer was added to each tube and applied to the flow cytometry for detection. The above experiments were repeated three times and analyzed statistically.

\section{Cell cycle detection by the PI method}

Cells in the logarithmic phase were collected, adjusted to a concentration of $1 \times 10^{6}$, washed twice with cold PBS, and then $75 \%$ ethanol at $-20^{\circ} \mathrm{C}$ was added and mixed evenly. The tubes were sealed and kept at $4^{\circ} \mathrm{C}$ overnight. Before detection, the cells were centrifuged and washed twice with PBS, then resuspended into $100 \mu \mathrm{l}$ of phosphate buffered saline (PBS) and treated with 
$0.5 \% \mathrm{PI}$ containing $0.01 \%$ RNase for $20 \mathrm{~min}$ at $4^{\circ} \mathrm{C}$. Cellular DNA contents were measured at $488 \mathrm{~nm}$ excitation wavelength. The above experiments were repeated three times and analyzed statistically.

\section{Detecting in vitro invasion by the transwell assay}

Equal amounts of HeLa cells in the logarithmic phase were added with $1: 100,1: 50$ or $1: 10$ semen, and then cultured for $48 \mathrm{~h}$. When the cells grew to $80 \%$ confluency, the medium was discarded and the plates were washed with PBS three times. Serum-free RPMI-1640 medium was added and cultured for $24 \mathrm{~h}$, and then the cells were centrifuged at $2000 \mathrm{rpm}$ for $5 \mathrm{~min}$ and the supernatant was collected and stored at $-20^{\circ} \mathrm{C}$ for future use. The transwell was placed in a 24-well plate; the polycarbonate film of the lower chamber was coated with fibronectin (FN, $0.2 \mathrm{mg} / \mathrm{ml}$ ) and dried on a clean bench. RPMI-1640 medium and Matrigel were mixed at an $8: 1$ ratio and spread onto the bottom polycarbonate film of the upper chamber and incubated at $37^{\circ} \mathrm{C}$ with $5 \% \mathrm{CO}_{2}$ for $30 \mathrm{~min}$ for gel formation. The plate was then irradiated with ultraviolet (UV) lamp overnight. Gel formation was conducted 30 min before the experiment, and $200 \mu \mathrm{l}$ of cell suspension $\left(1.0 \times 10^{6}\right.$ cells $/ \mathrm{ml}$ ) was inoculated into the upper chamber. Conditioned medium containing $13 \%$ calf serum was added to the lower chamber. After 12-h incubation, the film was removed and washed three times with PBS. The cells were fixed with 95\% ethanol for $15 \mathrm{~min}$ and stained with $0.1 \%$ crystal violet. Five visual fields were observed and counted under an optical microscope.

\section{Detection of protein expression by western blot}

Cells were collected and washed twice with cold PBS. Total protein was extracted and its concentration was determined by the Bicinchoninic Acid Kit (BCA kit). Then boiled denatured proteins were loaded (40 $\mu \mathrm{g}$ per well) and separated by sodium dodecyl sulfate-polyacrylamide gel electrophoresis (SDS-PAGE) using a 6\% stacking gel and $10 \%$ separating gel. The proteins on the gel were then transferred to a polyvinylidene difluoride (PVDF) membrane, which was blocked with $5 \%$ skim milk powder at $37^{\circ} \mathrm{C}$ for $2 \mathrm{~h}$. The membrane was incubated with 1 : 1000 dilutions of primary antibodies at $4^{\circ} \mathrm{C}$ overnight, then washed with Tris Buffered Saline with Tween 20 (TBST) three times (10 min each) and labeled with horseradish peroxidase-conjugated secondary antibodies (1: 500) at $4^{\circ} \mathrm{C}$ for $2 \mathrm{~h}$. After washing, an ECL luminescence kit was used to image the bands.

\section{Effects of semen on cervical cancer xenografts in nude mice}

HeLa cells in the logarithmic phase were collected and divided into two groups: one group went without semen treatment, while the other was treated with $1: 10$ semen for $48 \mathrm{~h}$. The cells were digested with $0.25 \%$ trypsin and $5 \times 10^{6}$ from each group was resuspended in PBS. Two groups of tumor cells ( $0.1 \mathrm{ml}$ from each group) were subcutaneously injected into both armpits of the nude mice to establish the model of human cervical cancer. Tumor nodules were formed after 2 weeks of inoculation. The length and width of the tumors were measured every 2 weeks. After 3 weeks, the mice were sacrificed by cervical dislocation. The transplanted tumors were isolated and the fat tissues on the tumor surface were removed. The length, width, and weight of the tumors were measured. Tumor volume $\left(V ; \mathrm{cm}^{3}\right)$ was calculated as: $V=L \times W^{2} / 2$. Tumor tissues were fixed, embedded, hematoxylin and eosin (HE) stained, and histomorphological differences between the control and experimental groups were observed.

\section{Statistical analysis}

SPSS 17.0 software (SPSS Inc., Chicago, IL, USA) was used for statistical analysis. $T$-tests were used for the analysis of single-factor two-level numeric data, and $p<0.05$ was considered statistically significant.

\section{Results}

There was no significant difference in apoptosis rate as Annexin- $\mathrm{V}^{+} / \mathrm{Pl}^{-}$(early apoptotic cells) and Annexin- $\mathrm{V}^{+} / \mathrm{PI}^{+}$(late apoptotic cells) were assessed within the untreated and seminal plasma treated HeLa cells ( $p>0.05$; Figures $1 \mathrm{~A}-\mathrm{E}$ ). However, treatment with seminal plasma significantly increased cell proliferation in HeLa cells, with the maximum increase observed at $1: 10$ concentration ( $p<0.05$; Figure $1 \mathrm{~F}$ ).

We next investigated the effect of seminal plasma on in vitro invasion of HeLa cells (Figure 2). The average number of invaded cells was 95 in the control group (Figure $2 \mathrm{~A}$ ), 134 in the $1: 100$ seminal plasma concentration group (Figure $2 \mathrm{~B}$ ), 170 in the $1: 50$ group (Figure 2 C) and 190 in the 1 : 10 group (Figure $2 \mathrm{D}$ ). There was a statistically significant difference between the control group and all experimental groups with seminal plasma, with a dose-dependent increase in invasion with seminal plasma concentration ( $p<0.05$; Figure $2 \mathrm{E}$ ).

We next investigated whether seminal plasma was causing ERK hyperactivation, which could explain the increase in HeLa cell proliferation observed with treatment of seminal plasma. 
A

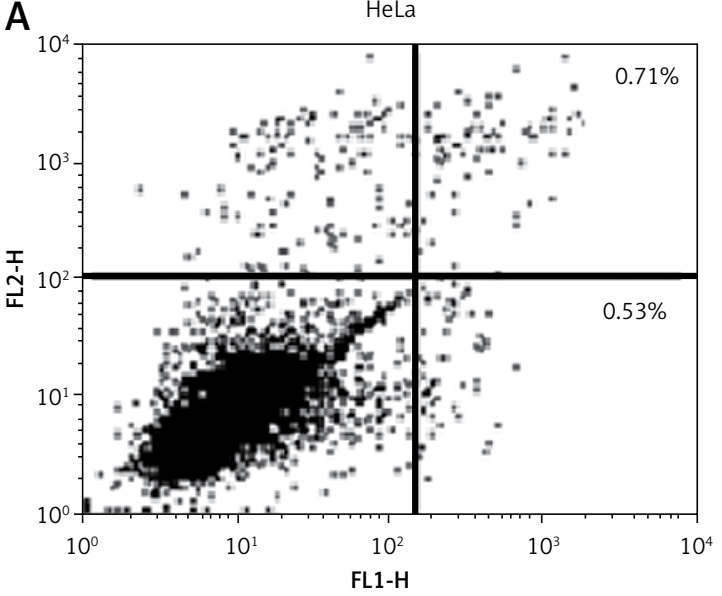

C

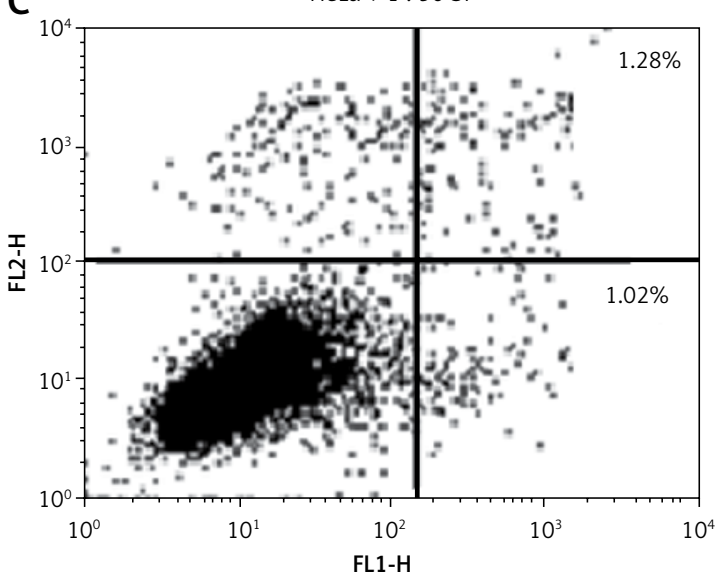

E

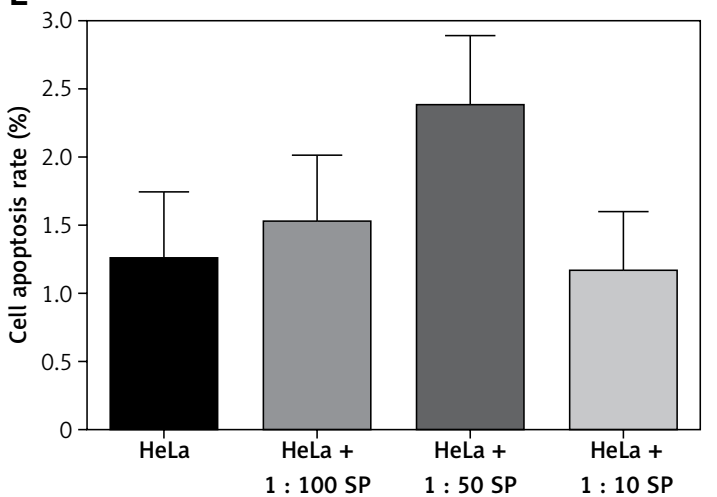

B

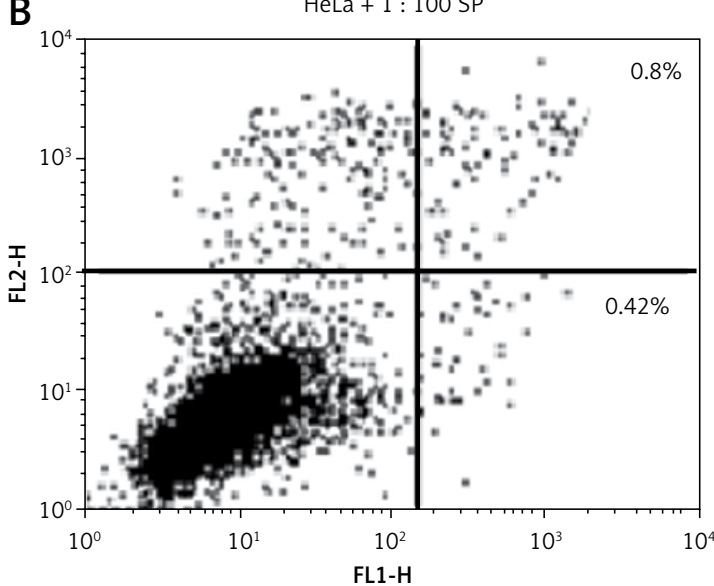

D

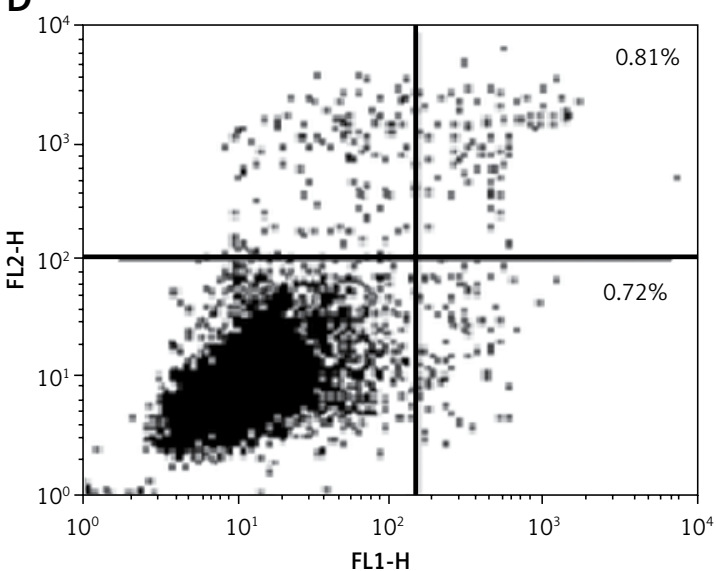

E

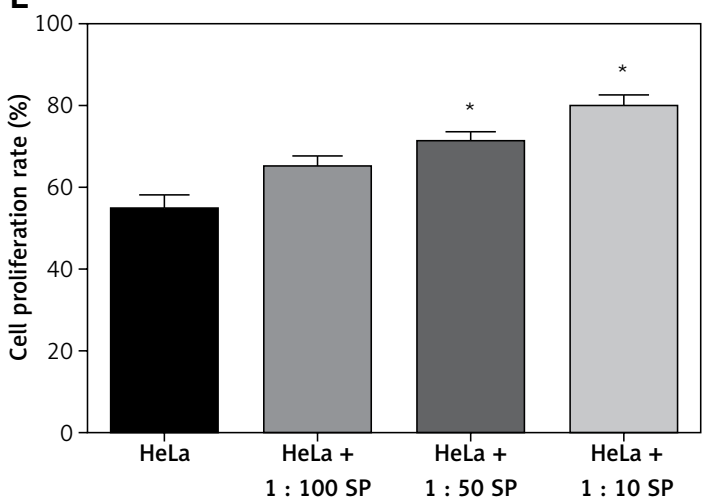

Figure 1. Seminal plasma induces cell proliferation, and not apoptosis, in HeLa cells. A-D - Apoptotic rate of HeLa cells stimulated by different seminal plasma concentrations. Representative flow cytometry plots and gating strategy for each of the four experimental groups are shown. Annexin- $\mathrm{V}^{+} / \mathrm{PI}^{-}$and Annexin- $\mathrm{V}^{+} / \mathrm{Pl}^{-}$were considered apoptotic. E - Quantification of three independent experiments. F- Quantification of cell proliferation in the indicated experimental groups by MTT assay

Data are represented as mean \pm standard deviation. ${ }^{*} P<0.05$ (t-test) versus HeLa. SP-seminal plasma.

When compared with the control group, each experimental group showed both increased MAPK pathway members expressed and increased ERK activation; the expression levels of ERK, p-ERK, C-MYC and MMP-9 were increased and the expression levels of P53 were decreased with seminal plasma treatment in a dose-dependent fashion (Figure 3).
The specificity of the observation was confirmed by co-treatment with the MAPK1 inhibitor U0126. Treatment with U0126 repressed seminal plasma-induced increase of ERK, p-ERK, C-MYC and MMP-9 expression as well as the suppression of P53 expression (Figure 4 A). Further, to determine the effects of ERK signaling on the proliferation of HeLa cells, U0126 was added into 
A

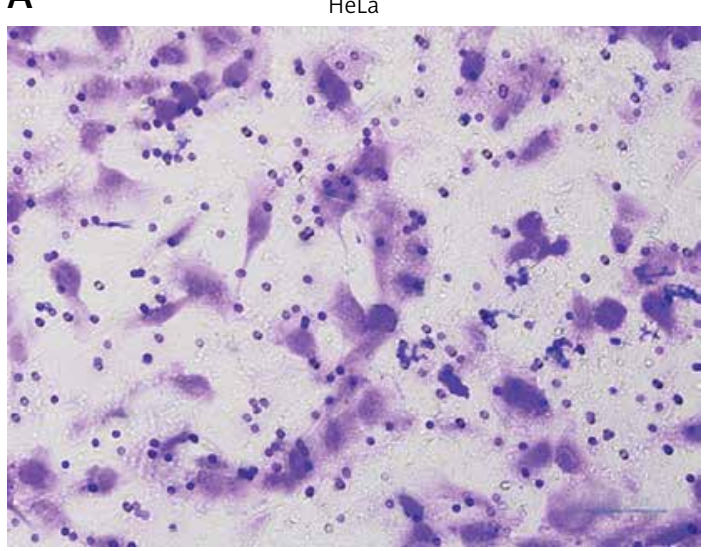

C

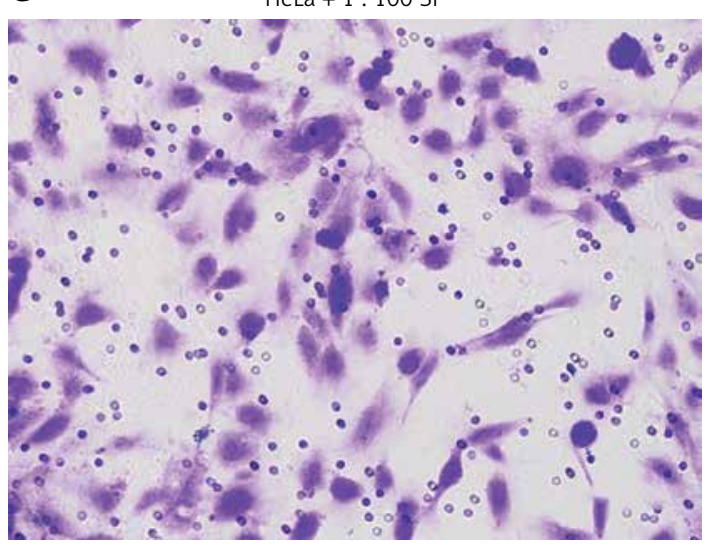

$\mathrm{E}$

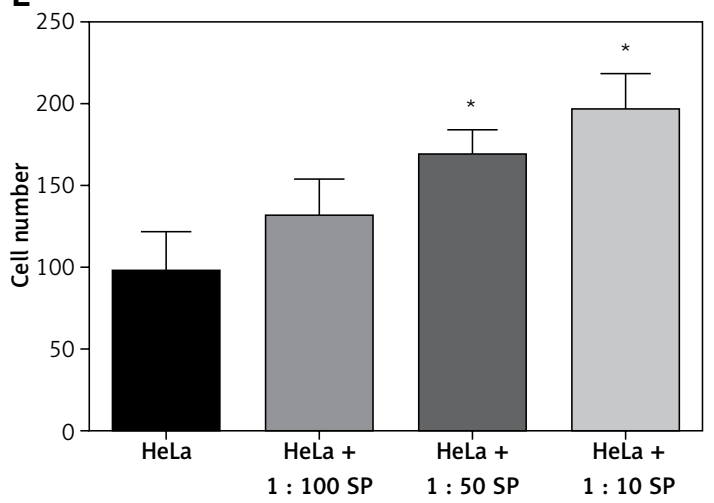

the experimental group containing $1: 50$ seminal plasma. Compared with the control group (without seminal plasma), the experimental group (1 : 50 seminal plasma) showed a significantly higher proliferation rate $(69.4 \%$ vs. $56.5 \%)$ which was reduced to $63 \%$ by $\mathrm{U} 0126$ (Figure $4 \mathrm{~B}$ ).

Given our observations that seminal plasma increased in vitro invasion, we next investigated whether seminal plasma would promote in vivo tumorigenesis. HeLa cells stimulated by seminal plasma formed transplanted tumors faster than the cells without stimulation. After 3 weeks, the average volume and weight of the tumors derived from stimulated HeLa cells were significantly greater than those derived from HeLa cells without
B
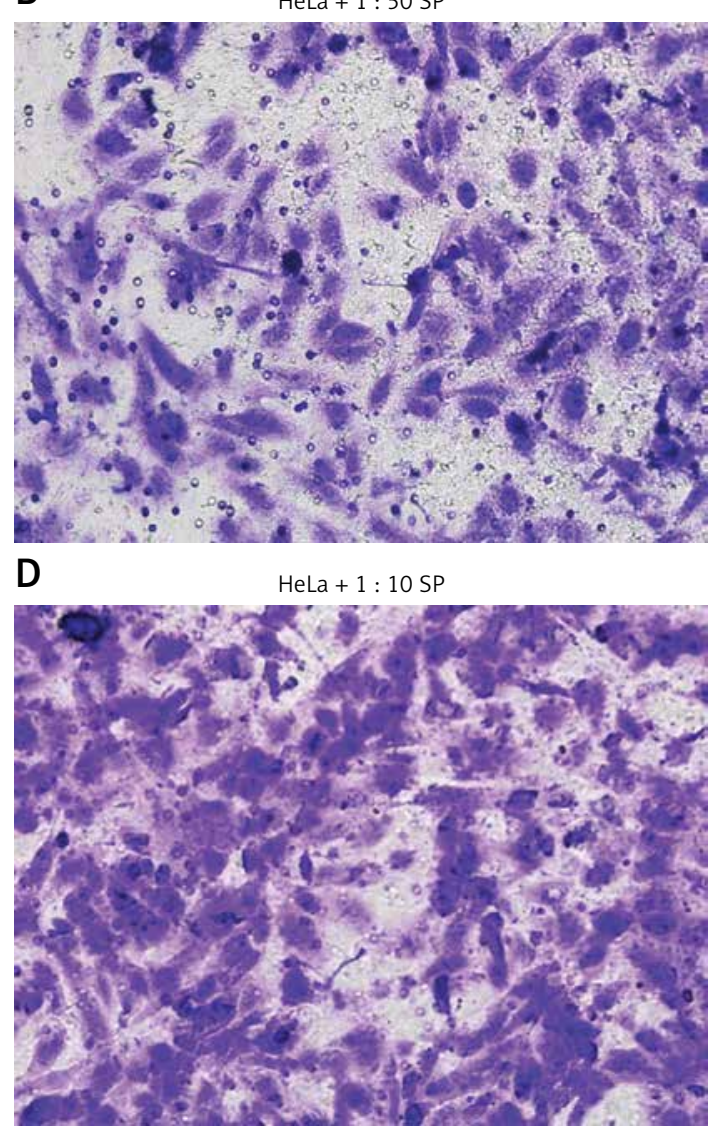

Figure 2. Seminal plasma induces in vitro invasion in HeLa cell. A-D Representative images of invaded cells for each of the four experimental groups are shown. Scale bar, $100 \mu \mathrm{m}$. E - Quantification of three independent experiments

Data are presented as mean \pm standard deviation. ${ }^{\star} P<0.05$ (t-test) versus HeLa. SP - seminal plasma.

seminal plasma stimulation $\left(1.24 \mathrm{~cm}^{3}\right.$ vs. $0.47 \mathrm{~cm}^{3}$ in volume and $3.66 \mathrm{mg}$ vs. $2.82 \mathrm{mg}$ in weight) $(p<0.05$; Figures $5 \mathrm{~A}-\mathrm{C})$.

Histopathological changes in the transplanted tumors were evaluated by $\mathrm{H}+\mathrm{E}$ staining (Figures 5 D, E). Tumor cells in both groups had similar pathological features and displayed characteristic atypia such as irregular cell shapes, large volumes, large and dark-stained nuclei, heterokaryosis, karyokinesis and high nucleo-cytoplasmic ratios, but tumors in the stimulated group were less differentiated, suggesting that they formed more aggressive tumors, in line with our observation that in vitro invasion increased with seminal plasma treatment. 

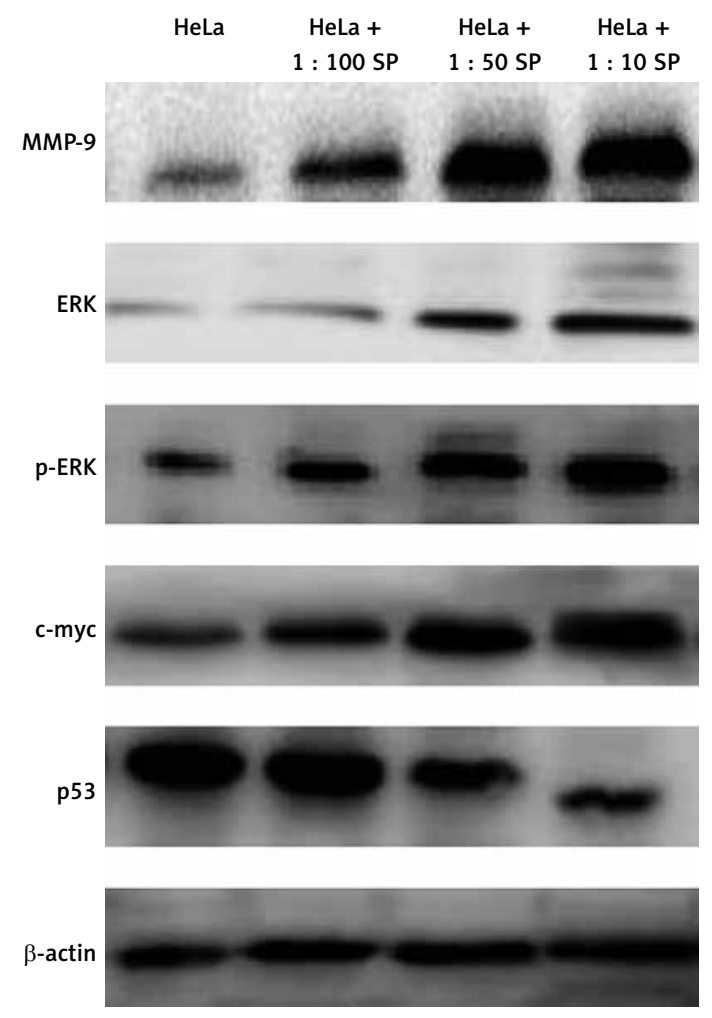

Figure 3. Western blot analysis of the effect of seminal plasma on MAPK pathway members and downstream targets in HeLa cells. Representative blot of three independent experiments is shown. $\beta$-actin was used as a loading control

$S P$ - seminal plasma.

\section{Discussion}

In this study, seminal plasma promoted the in vitro proliferation and invasion of cervical cancer cells. Previous studies showed that seminal plasma contains many components including estrogen, progesterone, a variety of cytokines and growth factors [10]. These components all regulate cell behavior. Seminal plasma stimulation can promote gene expression in endometrial epithelial cells and stromal cells, which is mediated by proinflammatory factors such as IL- $\beta$, IL- 8 and VEGF [11]. Recent studies have shown that the prostaglandins contained in seminal plasma can bind to the prostaglandin E2 and E4 receptor in cervical cancer cells and activate cyclooxygenase-2 in cancer cells, which further increases the expression of genes that promote tumor growth, thus leading to tumor cell proliferation and metastasis [12]. In our study, the effects of human seminal plasma on cell proliferation and invasion can potentially be attributed to these functional components mentioned above.

Our results showed that seminal plasma promoted cervical cancer cell proliferation and invasion by activating the ERK signaling pathway. The ERK cascade is an important signal transduction pathway in cells that transmits extracellular stim-
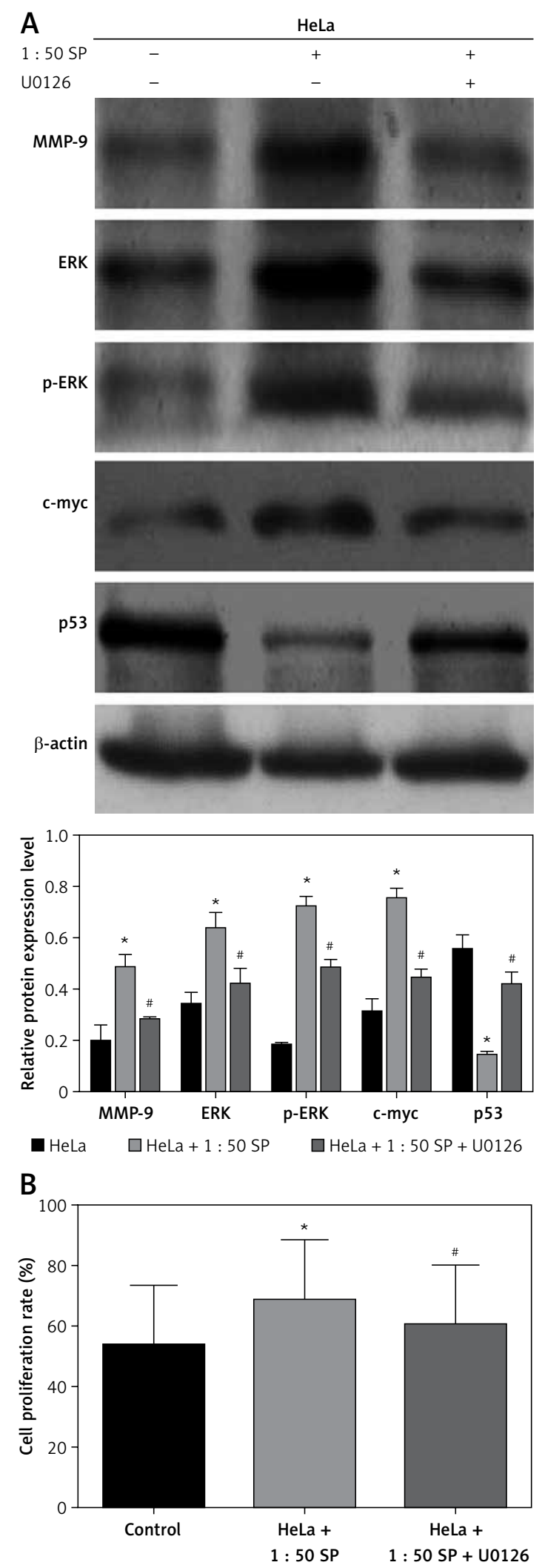

Figure 4. A - Effects of seminal plasma on proliferation of HeLa cells after addition of U0126 $(\bar{x} \pm$ s). B - Quantification of cell proliferation in the indicated experimental groups by MTT assay

Data are presented as mean \pm standard deviation. ${ }^{*} P<0.05$ (t-test) versus HeLa; ${ }^{*} P<0.05$ (t-test) versus HeLa $+1: 50$ SP. SP - seminal plasma. 
A

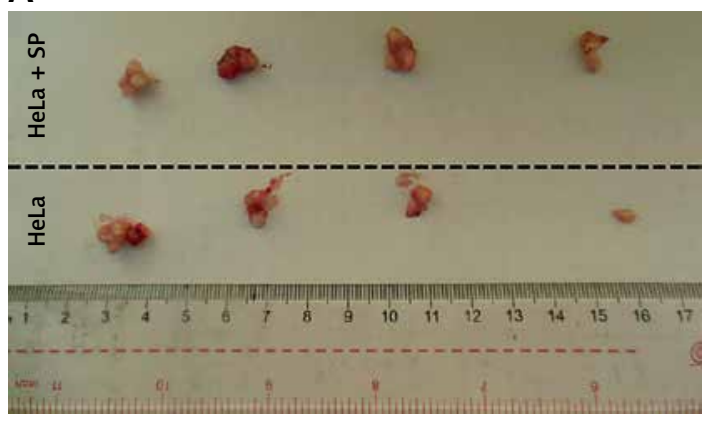

C
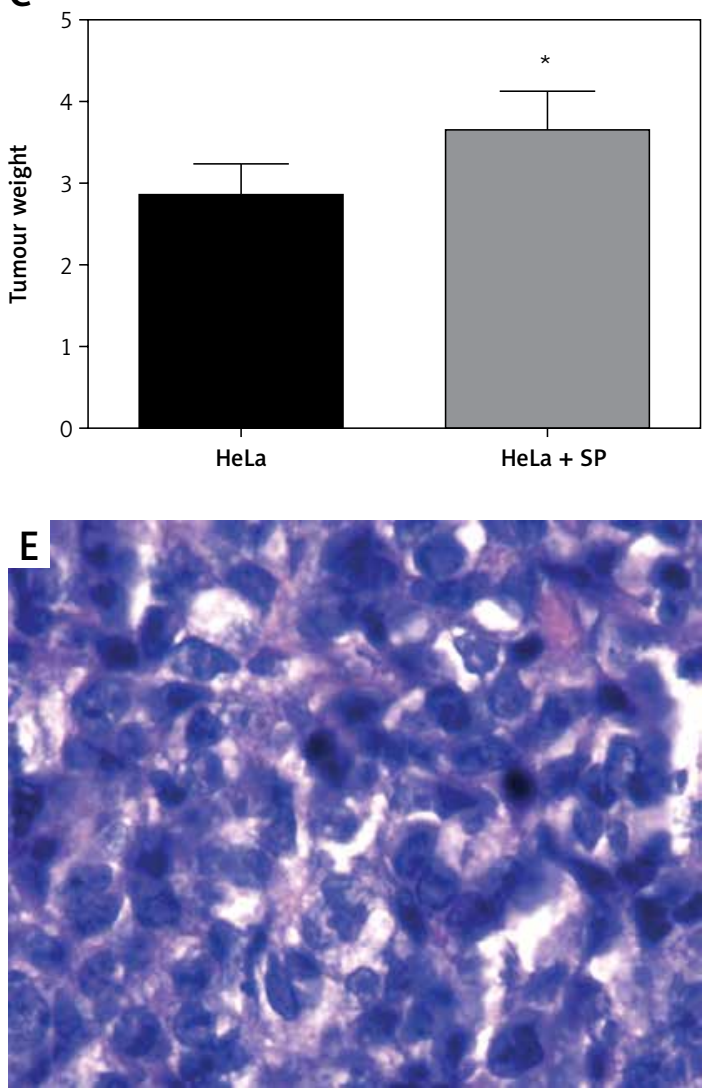

uli to the nucleus. ERK signaling participates in many physiological processes such as cell growth, development and differentiation. In unstimulated cells, ERK $1 / 2$ is mainly located in the cytoplasm, and once activated, ERK $1 / 2$ translocate to the nucleus, where it regulates the activity of certain transcriptional factors by phosphorylation. Abnormal ERK $1 / 2$ expression is closely associated with cell malignant transformation and tumor development $[13,14]$. It has been demonstrated that a variety of extracellular signals can activate ERK through various intracellular signaling molecules and pathways; however, the major pathway is the binding of growth factors or hormones to their receptors, which triggers the Ras-Raf-MEK-ERK cascade reaction [15]. Studies have shown that ERK and the associated signal pathways function as
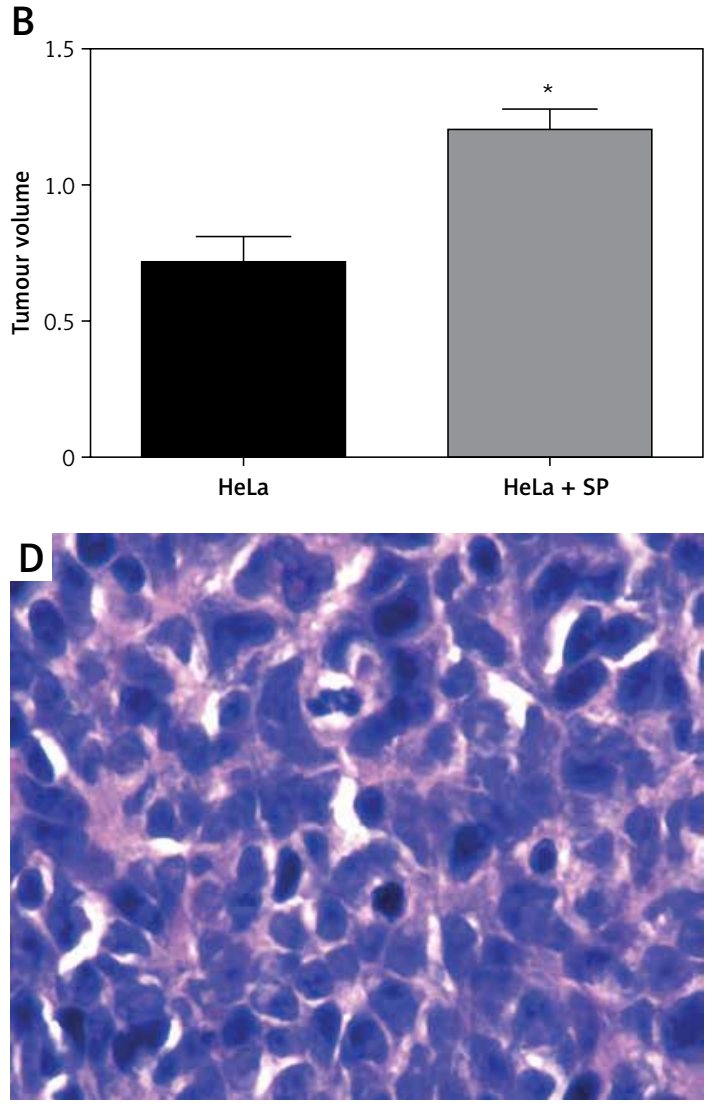

Figure 5. Seminal plasma makes HeLa cells more tumorigenic in vivo. A-C - Representative images of extracted tumors from untreated or seminal plasma (SP) stimulated HeLa cells (A), tumor volumes (B), and tumor weights (C). D, E - Representative $\mathrm{H}+\mathrm{E}$ staining images of extracted tumors in HeLa (D) and HeLa stimulated with SP (E) obtained at $400 \times$ magnification

${ }^{*} P<0.05$ (t-test) versus HeLa in $B$ and $C$.

mediators and signal amplifiers in the formation of cervical cancer and cancer invasion and metastasis [16]. The ERK pathway has been shown to be involved in the proliferation and invasion of cervical cancer cells induced by RAS mutation, while Mitra et al. $[17,18]$ found that ERK promoted the invasion of cervical cancer cells by activating MMP-2. Our findings are consistent with the above studies.

Our results showed that after cervical cancer cells were stimulated by seminal plasma, MMP-9 and c-myc expression were significantly up-regulated, which may contribute to the observed increase in cell proliferation and invasion. The downstream target genes in ERK signaling include MMP-9 and c-myc. MMPs are zinc-dependent protein endonucleases, which can degrade various protein 
components in the extracellular matrix (ECM) and destroy the histological barrier to facilitate tumor cell invasion. The MMPs are considered the most important proteolytic enzymes in tumor invasion and metastasis, especially MMP-9 [19]. The MMP-9 promotes tumor invasion and metastasis through two mechanisms: by degrading ECM and the basal plasma membrane of the vascular wall, and by promoting capillary angiogenesis of the tumor [20]. It was found that there are binding sites for transcription factors such as NF- $\mathrm{KB}$ in the promoter region of human MMP-9. Kim et al. [21] used cannabisin to inhibit the activity of NF- $\kappa \mathrm{B}$, and the expression of MMP-9 was significantly inhibited; the invasion and metastasis of breast cancer cells were also inhibited. This suggests that NF- $\mathrm{KB}$ can regulate the expression of MMP-9. C-myc is a well-known oncogene that is overexpressed in many cancers [22]. After translocating into the nucleus, P-ERK $1 / 2$ can interact with a variety of transcription factors including c-myc, c-fos, c-jun and NF- $\mathrm{kB}$, phosphorylating these nuclear transcription factors to regulate the transcription of related genes. It has been proven that c-myc plays a critical role in malignant transformation and oncogenesis [23]. These studies supported the critical role of MMP-9 and c-myc in promoting cell proliferation and invasion.

Our study provides a novel insight for preventing and treating cervical cancer and may have significance for reducing cervical cancer incidence. However, concerning the complexity of seminal plasma components, further studies are required to clarify the exact components of seminal plasma that regulate the survival, proliferation and invasion of cervical cancer cells, as well as their specific mechanisms of regulation. One limitation of the current study was that only one cervical cancer cell line was used. Additional validation in other cervical cancer cell lines is needed. Furthermore, semen samples from an increased number of males with different epidemiological characteristics need to be tested to correctly determine whether they play a role in the observed effects of semen on cervical cancer cells. Finally, the effect of serum on normal cervical cells needs to be determined.

In conclusion, to the best of our knowledge this is the first report that human seminal plasma promotes the proliferation of HeLa cells by activating the ERK pathway and enhances the in vitro invasiveness and in vivo tumorigenesis of cervical cancer cells. These findings indicate that human seminal plasma might be a potential factor contributing to the development of cervical cancer.

\section{Acknowledgments}

The study was supported by the National Science Foundation for Young Scientists of China (No. 81402138).

\section{Conflict of interest}

The authors declare no conflict of interest.

\section{References}

1. Jenal A, Bray F, Center MM, Ferlay J, Ward E, Forman D. Global cancer statistics.CA Cancer J Clin 2011; 61: 69-90.

2. Katki HA, Kinney WK, Fetterman B, et al. Cervical cancer risk for women undergoing concurrent testing for human papillomavirus and cervical cytology: a population-based study in routine clinical practice. Lancet Oncol 2011; 12: 663-72.

3. de Sanjose S, Quint WG, Alemany L, et al. Human papillomavirus genotype attribution in invasive cervical cancer: a retrospective cross-sectional worldwide study. Lancet Oncol 2010; 11: 1048-56.

4. Rodríguez AC, Schiffman M, Herrero R, et al. Longitudinal study of human papillomavirus persistence and cervcal intraepithelial neoplasia grade 2/3: critical role of duration of infection. J Natl Cancer Inst 2010; 102 : 315-24.

5. Li S, Zhu J, Li J, Li S, Li B. MicroRNA-141 inhibits proliferation of gastric cardia adenocarcinoma by targeting MACC1. Arch Med Sci 2018; 14: 588-96.

6. Sun SC. The non-canonical NF-kappaB pathway in immunity and inflammation. Nat Rev Immunol 2017; 17: 545-58.

7. Mathieu P, Bouchareb R, Boulanger MC. Innate and adaptive immunity in calcific aortic valve disease. J Immunol Res 2015; 2015: 851945.

8. Adefuye AO, Adeola HA, Sales KJ, Katz AA. Seminal fluid-mediated inflammation in physiology and pathology of the female reproductive tract. J Immunol Res 2016; 2016: 9707252.

9. Sales KJ, Adefuye A, Nicholson L, Katz AA. CCR5 expression is elevated in cervical cancer cells and is up-regulated by seminal plasma. Mol Hum Reprod 2014; 20: 1144-57.

10. Sales KJ, Adefuye A, Nicholson L, Katz AA. CCR5 expression is elevated in cervical cancer cells and is up-regulated by seminal plasma. Mol Hum Reprod 2014; 20 1144-57.

11. Gutsche S, von Wolff M, Strowitzki T, Thaler CJ. Seminal plasma induces RNA expression of IL-beta, IL- 6 and LIF in endometrial epithelial cells in vitro. Mol Hum Reprod 2003; 9: 785-91.

12. Sales KJ, Jabbour HN. Cyclooxygenase enzymes and prostaglandins in reproductive tract physiology and pathology. Prostaglandins Other Lipid Mediat 2003; 71: 97-117.

13. Hoffman L, Jensen CC, Yoshigi M, Beckerle M. Mechanical signals activate p38 MAPK pathway-dependent reinforcement of actin via mechanosensitive HspB1. Mol Biol Cell 2017; 28: 2661-75.

14. Shaul YD, Gibor G, Plotnikov A, Seger R. Specific phosphorylation and activation of ERK $1 \mathrm{c}$ by MEK $1 \mathrm{~b}$ : a unique route in the ERK cascade. Genes Dev 2009; 23: 1779-90.

15. Cubas R, Zhang S, Li M, Chen C, Yao Q. Trop2 expression contributes to tumor pathogenesis by activating the ERK MAPK pathway. Mol Cancer 2010; 9: 253.

16. Liu T, Liu Y, Bao X, Tian J, Liu Y, Yang X. Overexpression of TROP2 predicts poor prognosis of patients with cervical cancer and promotes the proliferation and invasion of cervical cancer cells by regulating ERK signaling pathway. PLoS One 2013; 8: e75864. 
17. Córdova-Alarcón E, Centeno F, Reyes-Esparza J, GarcíaCarrancá A, Garrido E. Effects of HRAS oncogene on cell cycle progression in a cervical cancer-derived cell line. Arch Med Res 2005; 36: 311-6.

18. Mitra A, Chakrabarti J, Banerji A, Das S, Chatterjee A. Culture of human cervical cancer cells, $\mathrm{SiHa}$, in the presence of fibronectin activates MMP-2. J Cancer Res Clin Oncol 2006; 132: 505-13.

19. Sharkey DJ, Macpherson AM, Tremellen KP, Robertson SA. Seminal plasma differentially regulates inflam matory cytokine gene expression in human cervical and vaginal epithelial cells. Mol Hum Reprod 2007; 13: 491501.

20. Singh W, Fields GB, Christov CZ, Karabencheva-Christova TG. Effects of mutations on structure-function relationships of matrix metalloproteinase-1. Int J Mol Sci 2016; 17: 1727.

21. Kim Y. Celastrol inhibits breast cancer cell invasion via suppression of NF-kappaB-mediated matrix metalloproteinase-9 expression. Cell Physiol Biochem 2011; 28 : 175-84.

22. El-Bassiouni A, Nosseir M, Zoheiry M, El-Ahwany E, Ghali A, El-Bassiouni N. Immunohistochemical expression of CD95 (Fas), c-myc and epidermal growth factor receptor in hepatitis $C$ virus infection, cirrhotic liver disease and hepatocellular carcinoma. APMIS 2006; 114 420-7.

23. Chen BJ, Wu YL, Tanaka Y, Zhang W. Small molecules targeting c-Myc oncogene: promising anti-cancer therapeutics. Int J Biol Sci 2014; 10: 1084-96. 